\title{
Representações Sociais e Grupo Focal: um estudo sobre a avaliação da aprendizagem em EAD ${ }^{1}$
}

\author{
Vania Maria de Oliveira Vieira \\ Universidade de Uberaba, Minas Gerais, MG - Brasil \\ vaniacamila@uol.com.br \\ Marilene Ribeiro Resende \\ Universidade de Uberaba, Minas Gerais, MG - Brasil
}

marilene.resende@uol.com.br

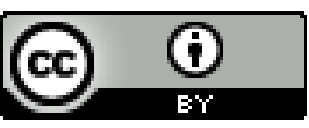

Educação: teoria e prática, Rio Claro, SP, Brasil - elSSN: 1981-8106

Está licenciada sob Licença Creative Common

\section{Resumo}

Este artigo tem como referência parte de uma pesquisa realizada com o suporte teóricometodológico da Teoria das Representações Sociais. Enfoca, especificamente, discussões e reflexões sobre avaliação da aprendizagem em cursos a distância. Os dados foram coletados a partir de grupos focais realizados com alunos concluintes do curso de Pedagogia de dois polos de uma Instituição de Ensino - Polos Cariacica e Colatina, no Espírito Santo. Apresenta como objetivo identificar as Representações Sociais que os alunos concluintes de Pedagogia em EAD estão construindo sobre a avaliação da aprendizagem. A análise dos dados identificou três palavras-chave: contradições, rituais e percepções, que foram traduzidas em três unidades de significado. Essas unidades associam-se às representações sociais construídas pelos sujeitos. A partir de suas vivências, falas, imagens, opiniões, estão organizando e materializando suas representações em sentimentos que denotam ser a avaliação primordial e necessária para a aprendizagem no curso, mas, ao mesmo tempo, convivem com contradições entre o que se ensina na teoria e o que se vivencia na prática, o que os leva a reivindicar um processo de avaliação mais humanizado.

Palavras-chave: Avaliação. Educação a Distância. Representações Sociais. Grupo Focal.

\footnotetext{
${ }^{1}$ Este artigo tem como referência pesquisa realizada com o financiamento da Fundação de Amparo a Pesquisa de Minas Gerais - FAPEMIG. Insere-se no âmbito de uma investigação maior, coordenada pelo Centro Internacional de Estudos em Representações Sociais e Subjetividade - educação - CIERS-Ed.
} 


\title{
Social Representations and Focus Group: a study on the assessment of learning in distance education.
}

\begin{abstract}
This article derives partially from a theoretical-methodological research, carried out with the support of Social Representations Theory. It focuses specifically on discussions and reflections on learning assessment in distance education. The data were collected from focus groups, gathered from graduating students of Pedagogy of two poles of an Educational Institution, Cariacica and Colatina poles, in the State of Espirito Santo. The objective was to identify the social representations which the graduating students of Pedagogy in distance education built about the assessment of learning. The data analysis identified three key words: contradictions, rituals and perceptions which were translated into three unities of meaning. These unities are associated with the social representations, built by those students. From their experiences, speeches, pictures and viewpoints, they organized and transformed their representations into feelings which denote that assessment is primordial and necessary for learning in the course; yet at the same time, they met contradictions, between what is taught in theory, and what is experienced in practice, what leads them to fight for a more humane evaluation process.
\end{abstract}

Keywords: Evaluation. Distance Education. Social Representations. Focus Group.

\section{Introdução.}

Este texto, parte integrante de uma pesquisa sobre Representações Sociais, traz à tona discussões e reflexões acerca da avaliação da aprendizagem em cursos de formação de professores na modalidade a distância.

Partimos do princípio de que, pensar a avaliação nos remete a discutir a escola, a formação docente e os processos de aprendizagem. E, em se tratando de educação a distância, cabe perguntar: o que muda nessa modalidade de ensino? Podem as concepções, os procedimentos ser os mesmos dos adotados no ensino presencial, dado que o espaço da aula e da formação são outros?

Não se pode ignorar que, no contexto de maiores possibilidades de rompimento de barreiras de espaço e de tempo e de novas necessidades educativas, a Educação a Distância (EAD) vem se expandindo de forma espantosa, principalmente na formação inicial e continuada de profissionais, nas mais diversas áreas, acentuadamente na formação de professores para a educação básica. Esse tem sido no Brasil um campo aberto e propício às experiências, concebidas e implementadas por meio de políticas e iniciativas públicas, como também de investimento das instituições privadas de ensino, o que, consequentemente, traz 
muitas questões em vários aspectos. Muitas delas conduzem à necessidade de pesquisa e reflexão, como é o caso das práticas pedagógicas, nelas incluída a avaliação.

Para os seus defensores, a EAD surge como uma alternativa de superação do individualismo e construção de um novo tempo, em que toda a coletividade possa participar, de fato e de direito, no processo de organização da sociedade.

Porém, ao lado dessa abertura para a implantação de cursos superiores na modalidade a distância, observa-se, conforme nos mostra Barreto (2003), que as políticas educacionais, ao tratarem da formação de professores nos países em desenvolvimento, propõem programas de certificação em larga escala e de menor custo, o que, aliado a uma fetichização da tecnologia, pode provocar a fragmentação da formação docente, inicial e continuada, e a precarização do trabalho docente. Nesse sentido, estudos e pesquisas que envolvam os cursos de formação de professores nessa modalidade se fazem necessários.

Com relação à avaliação, como também se observa no ensino presencial, várias têm sido as concepções presentes nos programas de educação a distância, assim como nos discursos e práticas dos envolvidos no processo.

Como mostram pesquisadores do campo, a avaliação tem se constituído em objeto de estudo, seja a avaliação da aprendizagem, como a avaliação institucional, como a avaliação sistêmica, tão valorizada nos últimos anos. Assim, cada vez mais a avaliação tornase alvo, não só de indagações e reflexões, como também de controvérsias. Essas reflexões têm produzido diferentes discussões que resultam, por sua vez, em diferentes movimentos. Alguns, questionando os processos de avaliação classificatória e excludente, e outros, visando ao aperfeiçoamento das práticas avaliativas, como indispensáveis para uma escola de qualidade (ESTEBAN, 2008).

A avaliação, caracterizada como um ritual com a finalidade de classificação, deixa de ser um meio para identificar causas de sucesso ou fracasso escolar, servindo apenas de instrumento para julgar e classificar os alunos. Torna-se, portanto, improdutiva, sem condições de transformar ou aprimorar o processo de aprendizagem, constituindo-se em meio de controle dos alunos (SOUSA, 2003)

Ao relatar uma investigação com pesquisadores da área, Sousa $(2003$, p. 110) aponta que a avaliação do rendimento escolar tem-se traduzido: 
[...] em uma prática autoritária que legitima um processo de seletividade e discriminação de alunos, com consequências sociais e pessoais danosas, em nada coerente com a função que foi atribuída, de apoiar o aperfeiçoamento do ensino". Afirma ainda que sua preocupação, advinda de uma profunda insatisfação com o desempenho da avaliação do rendimento escolar, é a de "recuperar um conhecimento avaliativo compromissado com uma educação transformadora.

Considerando que a avaliação é um componente importante do processo de ensino e aprendizagem, com funções que vão além da medição e da classificação; considerando, ainda, que o ensino a distância tem particularidades que não podem ser ignoradas e que podem afetar diretamente as práticas avaliativas, é que essa investigação foi realizada. Conhecer as representações sociais que esses estudantes, futuros professores, a quem caberá avaliar os seus alunos, é relevante, pois se sabe que há uma tendência de que as práticas vivenciadas sejam reproduzidas. Elegemos, assim, a avaliação da aprendizagem em cursos na modalidade a distância como objeto de estudo, com o intuito de instigar algumas reflexões e discussões sobre essa temática.

\section{Objetivo e Metodologia: a contribuição da Teoria das Representações Sociais}

Esta pesquisa, de caráter qualitativo, tem o objetivo de identificar as Representações Sociais que os alunos concluintes do curso de Pedagogia na modalidade a distância estão construindo sobre a avaliação da aprendizagem. Intenciona, também, recuperar conhecimentos avaliativos que primam por uma educação transformadora e compromissada com a aprendizagem dos alunos.

Para isso, na pesquisa foram aplicados 212 questionários a alunos concluintes do curso de Pedagogia a distância, de diversos polos - Triângulo (Araxá, Uberaba, Uberlândia); Espírito Santo (Cariacica, Colatina) e Regional Triângulo Mineiro (São Gotardo). A aplicação ocorreu durante os encontros presenciais nos respectivos polos. Todos os alunos presentes no dia da aplicação foram convidados a participar.

O questionário, com questões abertas e fechadas, referia-se à identificação do perfil dos sujeitos e das Representações Sociais construídas por eles sobre a avaliação da aprendizagem. O perfil identificou aspectos sociais, econômicos e culturais dos alunos, e as representações foram identificadas por meio de questões específicas. 
Após análise das questões do questionário, foi realizada a técnica do Grupo Focal com dois grupos de sujeitos, com o intuito de complementar e suplementar as informações obtidas no questionário, numa situação de interação e co-construção de significados.

As transcrições do grupo focal foram analisadas sob a orientação dos pressupostos de Bardin (1977) e Minayo (2003), tendo como aporte a teoria das Representações Sociais de Moscovici, e constitui, neste artigo, o foco central das discussões.

Para Bardin (1977), a análise de conteúdo pode ser conceituada como um conjunto de técnicas de análise que visa obter, por meio de procedimentos sistemáticos e objetivos, descrições de conteúdos de mensagens (comunicações, quantitativos ou não). Essas análises permitem a inferência de conhecimentos referentes às comunicações. Segundo Minayo (2003, p. 74), a análise de conteúdo tem como objetivo verificar hipóteses e/ou descobrir o que está por trás de cada conteúdo manifesto: “(...) o que está escrito, falado, mapeado, figurativamente desenhado e/ou simbolicamente explicitado sempre será o ponto de partida para a identificação do conteúdo manifesto (seja ele explícito e/ou latente)."

A Teoria das Representações Sociais tem sua origem na sociologia de Durkheim - foi desenvolvida por Serge Moscovici e aprofundada por Denise Jodelet. Émile Durkheim era francês (1858/1917) e foi considerado, junto com Max Weber, um dos fundadores da sociologia moderna. Serge Moscovici, também francês, nasceu em 1928, é psicólogo social, considerado o idealizador da teoria das Representações Sociais. Denise Jodelet, professora francesa, introduziu o estudo das representações sociais no Brasil. Coordena um grupo de estudos e pesquisas, cuja perspectiva teórica é mais fiel a Moscovici.

O conceito Representações Sociais surgiu em 1961, na França, com a obra de Moscovici, "La Psychanalyse, son image, son public", resgatando o conceito de representação coletiva de Durkheim - mas com algumas diferenças. Para Durkheim (1898), as representações são coletivas, permanentes, tradicionais, amplamente distribuídas, ligadas à cultura, transmitidas lentamente por gerações. Para ele, o fenômeno social não depende da natureza pessoal dos indivíduos. Já para Moscovici (1961), as representações são sociais, dinâmicas, típicas de culturas modernas, espalham-se rapidamente por toda a população, possuem curto período de vida. Para ele, o indivíduo tem um papel atuante e particular na construção das representações sociais. 
Entende-se, aqui, que a representação coletiva, ao ser substituída por representação social, deixa de ser um conceito que explica o conhecimento e crenças de um grupo para se tornar um fenômeno que exige explicação e que produz conhecimento.

A Psicologia Social, desde sua existência, convive com a angústia de incorporar duas vertentes antagônicas: o psicológico, de um lado, entendido como algo individual; e o social, por outro lado, entendido como algo diferente ou até oposto ao individual. A Teoria das Representações Sociais supera essa dicotomia, que se formou no decorrer da história da Psicologia Social - possui uma dimensão individual na medida em que ela necessita ancorarse em sujeitos para que possa ser entendida como existente, mas é, igualmente, social, pois existe "na mente e na mídia" (MOSCOVICI, 1984, apud GUARESCHI, 2000, p. 250)

Para Jodelet (1989), as representações "são uma forma de conhecimento elaborada e partilhada socialmente, tendo uma visão prática e concorrendo à construção de uma realidade comum a um conjunto social”. Essas representações apresentam características fundamentais: é sempre representação de um objeto; tem sempre um caráter imagético e a propriedade de deixar intercambiáveis a sensação e a ideia, a percepção e o conceito; tem um caráter simbólico, significante, construtivo, autônomo e criativo.

Para Moscovici (2003, p. 40), todas as interações humanas, sejam elas entre duas pessoas ou entre dois grupos, pressupõem representações: "sempre e em todo lugar, quando nós encontramos pessoas ou coisas e nos familiarizamos com elas, tais representações estão presentes".

\footnotetext{
As representações sociais são entidades quase tangíveis. Elas circulam, se entrecruzam e se cristalizam continuamente, através de uma palavra, dum gesto, ou duma reunião, em nosso mundo cotidiano. Elas impregnam a maioria de nossas relações estabelecidas, os objetos que nós produzimos ou consumimos e as comunicações que estabelecemos. Nós sabemos que elas correspondem dum lado, à substância simbólica que entra na sua elaboração e, por outro lado, à prática específica que produz essa substância, do mesmo como a ciência ou o mito correspondem a uma prática científica ou mítica (MOSCOVICI, 2005, p. 10).
}

Sintetizando, para Moscovici (2003), as representações são expressões do conhecimento reconstruído pelo sujeito a respeito de sua realidade cotidiana; expressam a forma como cada grupo social se organiza e constrói seus significados; fazem uma ponte 
entre o conhecimento de senso comum e o científico; tornam o não familiar em algo familiar.

Segundo Moscovici (1961/1976, apud TRINDADE, SANTOS E ALMEIDA 2011, p. 107) "quando o sujeito exprime suas opiniões e atitudes sobre um objeto ele já formulou uma representação deste objeto, o que equivale dizer que estímulo e resposta se formam junto, ao contrário da dicotomia até então sustentada".

Para melhor identificar as representações sociais dos sujeitos, necessitamos compreender os processos de objetivação e ancoragem descritos por Moscovici (2003) e Jodelet (1992). Esses processos estão intrinsecamente ligados um ao outro e são modelados por fatores sociais. De modo geral, eles mostram como o social transforma um conhecimento em representação e como essa representação transforma o social (JODELET, 1992, apud CHAMON, 2006).

Segundo Chamon (2006, p. 23), a objetivação "é o processo que torna concreto o que é abstrato, que materializa a palavra, que transforma o conceito em objeto e os torna intercambiáveis [...] ela substitui o conceito pelo que é percebido, o objeto pela sua imagem". Acresce ainda, citando Rouquette (1994, p.172), que a objetivação "é vista como forma de verdade [...]e a maior parte do tempo, cada um está convencido de que fala da realidade das coisas, quando apenas exprime sua própria compreensão daquilo que percebe".

Dito de outra forma, a objetivação diz respeito "à forma como se organizam os elementos constituintes da representação e ao percurso através do qual tais elementos adquirem materialidade, isto é, se tornam expressões de uma realidade vista como natural"(CABECINHAS, 2004, p. 6).

Quanto à ancoragem, Trindade, Santos e Almeida (2011, p. 110) explicam que este processo "permite ao indivíduo integrar o objeto da representação em um sistema de valores que lhe é próprio, denominando e classificando-o em função dos laços que este objeto mantém com sua inserção social". Acresce, ainda, que, nesta mesma direção, "um novo objeto é ancorado quando passa a fazer parte de um sistema de categorias já existentes, mediante alguns ajustes". Dito de outra forma, a ancoragem é um processo que aproxima o que é estranho, perturbador, sem sentido, ao que pode ser comunicado, integrando-o a alguma categoria já existente. 
Nesse sentido, podemos dizer que os processos de objetivação e ancoragem promovem a familiarização com o novo, permitindo, inicialmente, a integração do objeto num quadro de referência em que pode ser interpretado e depois reproduzido e colocado sob controle (MOSCOVICl, 1978). Está aí a grande contribuição das pesquisas em representações sociais.

É disso que os nossos estudos tratam. Com o auxílio de entrevistas de grupos focais, procuramos tornar familiar o não familiar acerca das representações que estão sendo construídas sobre a avaliação da aprendizagem em curso de formação de professores na modalidade a distância. Tomamos como princípio que a teoria das Representações Sociais, entendida neste estudo como um suporte teórico-metodológico, tem o objetivo de explicar os fenômenos do homem a partir de uma perspectiva coletiva, sem perder de vista a individualidade. E, como finalidade, a de tornar familiar algo não familiar, de classificar, categorizar, dar nomes a novos acontecimentos e ideias. (MOSCOVICI 2003).

As representações são saberes do senso comum construídas nas relações entre os indivíduos. No cotidiano, as pessoas conversam, pensam, analisam, sobre os mais diferentes temas e elaboram representações. Essas representações passam a influenciar suas relações e comportamentos sociais (GUARESCHI; NAUJORKS, 2006, p.3-4)

Com a elaboração das representações sociais, transformamos o novo, o desconhecido, em algo familiar. Enquanto que o não familiar intriga e gera desconforto, o familiar é, para nós, o conhecido, a confirmação de nossas crenças. Assim, "o ato de reapresentação é um meio de transformar o que nos perturba, o que ameaça nosso universo, do exterior para o interior, do longínquo para o próximo" (MOSCOVICl,2003, p.56). Neste caso, buscamos conhecer como os alunos concluintes do curso de Pedagogia a distância percebem a avaliação da aprendizagem à qual são submetidos.

\section{A proposta de avaliação da aprendizagem na legislação e no curso pesquisado.}

O curso de Pedagogia, em estudo, é ofertado por uma instituição credenciada para a modalidade de ensino a distância desde 2005.

O Projeto Pedagógico do Curso prevê a formação do professor-educador-gestor. Sua elaboração atende ao previsto nas Diretrizes Curriculares Nacionais para o curso de Pedagogia- Resolução CNE/CP no 1, de 15 de maio de 2006. O curso é organizado em três 
anos e meio, com duas etapas em cada ano. Durante cada etapa, estão previstos momentos de encontros presenciais, que são divididos em quatro oficinas de apoio à aprendizagem, com carga horária de oito horas cada uma, e dois seminários de integração, com dezesseis horas cada um.

Com relação à avaliação, o projeto prevê que esta deve se realizar ao longo do curso, de forma processual e formativa, com o objetivo de possibilitar, ao preceptor ${ }^{2}$ e ao aluno, identificar os conhecimentos construídos em cada etapa do processo de aprendizagem. As avaliações devem ser realizadas com instrumentos variados, visando acompanhar o aluno de forma global. As provas escritas, individuais, são realizadas em momentos presenciais, a cada etapa. A nota do aluno é representada numericamente numa escala de 0 a 10 pontos, conforme as normas internas da instituição, a saber: 100 pontos para a avaliação processual, realizada no decorrer da etapa, e 200 pontos para duas avaliações presenciais, com duração de 4 horas cada uma. O processo de avaliação inclui momentos de autoavaliação dos alunos, preceptores e equipe multidisciplinar.

A avaliação da aprendizagem na modalidade a distância está prevista no Decreto 5.622, de 19/12/2005, que estabelece a obrigatoriedade de avaliações presenciais e a prevalência dessas sobre as outras formas a serem estabelecidas pelas instituições.
A avaliação do desempenho do estudante para fins de promoção, conclusão de estudos e obtenção de diplomas ou certificados dar-se-á no processo, mediante:
I - cumprimento das atividades programadas; e
II - realização de exames presenciais (BRASIL, 2005).

Os Referenciais de Qualidade para Educação Superior a Distância (BRASIL, 2007) propõem uma avaliação que promova a aprendizagem dos alunos de modo a desenvolver competências cognitivas, habilidades e atitudes cada vez mais complexas. E, para tal, indicam:

[...] esta avaliação deve comportar um processo contínuo, para verificar constantemente o progresso dos estudantes e estimulá-los a serem ativos na construção do conhecimento. Desse modo, devem ser articulados mecanismos que promovam o permanente acompanhamento dos estudantes, no intuito de

\footnotetext{
2 “O preceptor é responsável pelo acompanhamento do discente em EAD na instituição, esclarecendo dúvidas, estimulando reflexões sobre conteúdos das etapas, orientando na construção do Trabalho de Construção de Aprendizagens (TCC), atividades de estágio, dentre outras" (RESENDE; VIEIRA, 2010, p. 5).
} 
identificar eventuais dificuldades na aprendizagem e saná-las ainda durante o processo de ensino-aprendizagem (BRASIL, 2007, p. 16).

Os referenciais recomendam, também, que medidas de segurança e de confiabilidade sejam garantidas pelas IES, em relação aos momentos de avaliação presencial.

\section{A entrevista de grupo focal}

A entrevista ou método de Grupo Focal, segundo Flick (2009, p. 180), tem sido muito utilizada em pesquisas qualitativas. Esse tipo de método contrasta com a narração que se produz na forma de monólogo na entrevista narrativa. Amplia-se o escopo da coleta de dados, tenta-se coletar os dados dentro do contexto, o que possibilita situações de interações próximas da vida cotidiana dos sujeitos. Para esse autor, entrevistar grupos de pessoas amplia consideravelmente a situação da entrevista. "Uma entrevista tipo grupo focal é uma entrevista com um pequeno grupo de pessoas sobre um tópico específico. Em regras, os grupos são formados por 6 a 8 pessoas que participam da entrevista por um período de 30 minutos a 2 horas" (PATTON, 2002, apud FLICK, 2009, p. 181).

Flick (2009, p.181) recomenda que o entrevistador de um grupo focal deva ser "flexível, objetivo, empático, persuasivo, um bom ouvinte". Acresce, ainda, que a sua principal tarefa é a de "impedir que participantes individuais ou grupos parciais dominem, com suas contribuições, a entrevista e, consequentemente, todo o grupo". Patton (2002 apud Flick, 2009) entende a entrevista de grupo focal como uma técnica qualitativa altamente eficaz no sentido de fornecer alguns controles de qualidade em relação à coleta de dados. Afirma que os participantes, durante a entrevista, tendem a contrabalançar uns aos outros, isto é, impedem opiniões falsas ou radicais.

Flick (2009) traça algumas recomendações acerca da condução da entrevista de grupo focal: o número de grupos focais depende da questão da pesquisa e do número de subgrupos da população pesquisada; aconselha-se trabalhar com pessoas estranhas, evitando grupos de amigos ou de pessoas que se conhecem bem; deve-se começar com grupos mais heterogêneos, para, então, reunir um segundo conjunto mais homogêneo; iniciar sempre as entrevistas com algum tipo de aquecimento; criar um clima liberal, de informalidade, facilitando a contribuição dos membros, para que possam falar abertamente 
suas experiências e opiniões. Como técnica analítica, sugere-se a utilização de análises de conteúdos.

Neste estudo, as entrevistas de grupo focal foram realizadas durante os encontros presenciais nos polos. O convite foi feito a todos os alunos, e os primeiros que manifestaram desejo de participar compuseram os grupos. O primeiro foi constituído por sete alunos, e o segundo, por oito. Chamaremos de GF01 e GF02, e os nomes dos componentes dos grupos, por questões éticas, foram substituídos por nomes fictícios.

Nossa intenção foi a de explorar um pouco mais o objeto de estudo da pesquisa: a avaliação da aprendizagem em curso de formação de professores na modalidade a distância. Assim, mediante um clima informal e descontraído, permitimos aos integrantes conversarem entre si a partir de temas sugeridos por nós. Iniciamos com uma pergunta ampla - a partir da experiência de vocês, como alunos de ensino na modalidade a distância, gostaríamos que relatassem, expressando a opinião, os sentimentos, as percepções sobre como tem sido a avaliação da aprendizagem ao longo do curso - e, em seguida, as discussões e os debates giraram em torno das questões: Como são avaliados? Como percebem a avaliação? O que sentem ao serem avaliados? Qual a importância dessa avaliação para o processo de aprendizagem? Em que condições as avaliações são aplicadas? São condições favoráveis ou condições que prejudicam a aprendizagem?

Para análise dos dados, realizamos várias leituras das transcrições das gravações em áudio. Em seguida, identificamos três palavras-chave: contradições, rituais e percepções. Essas palavras foram traduzidas em três temas, que, segundo Bardin (1977), constituem unidades de significado: a) avaliação da aprendizagem na EAD: contradições entre o que se propõe, o que se ensina e o que se vivencia; b) os ritos e os rituais da avaliação presencial num curso a distância: a reivindicação por um processo mais humanizado; c) avaliação a distância na percepção dos alunos.

Os resultados encontrados nesses temas associam-se às representações sociais construídas pelos alunos. Apontam para alguns indicadores em relação à avaliação da aprendizagem na EAD, que devem ser considerados, discutidos e refletidos enquanto mazelas que ainda subjazem na formação de professores. A seguir, apresentamos cada um desses temas, esclarecendo que, ao inserir a fala dos entrevistados, procuramos mantê-las com as marcas da linguagem coloquial. 
a) Avaliação da aprendizagem na EAD: contradições entre o que se propõe, o que se ensina e o que se vivencia.

Diversos autores, como Vasconcellos (1998), Haydt (2000), Luckesi (2011) Hoffmann (1995) e outros, destacam as contradições existentes entre teoria e prática, quando se trata de avaliar a aprendizagem dos alunos. Afirmam que há contradições entre o que se ensina na teoria e o que se vivencia na prática. Esse tema foi amplamente contemplado durante os debates nos grupos focais.

A teoria que passam pra gente são textos belíssimos, dizem que o método pra se avaliar o aluno não é somente aquela avaliação final. Falam em avaliação formativa [...] só que a prática aplicada é totalmente diferente. (GF 01/PEDRO).

Desde o início desse curso foi falado muito sobre "prova tradicional", e essas avaliações, como são passadas pra nós, são tradicionais realmente, é aquele negócio, é tenso, todo mundo fica ansioso, no período da tarde, é horrível. (GF 01/SAMARA).

Segundo Perrenoud (1999, p. 11), classificar o desempenho do aluno durante o processo de avaliação é um dos meios mais tradicionais, presentes ainda nas escolas. "A avaliação é tradicionalmente associada, na escola, à criação de hierarquias de excelência. Os alunos são comparados e depois classificados em virtude de uma norma de excelência".

\footnotetext{
Estudamos que todo processo de avaliação tem que avaliar o seu aluno constantemente, não pode taxá-lo de nada, não se deve aplicar avaliação classificatória, só que quando a gente olha, está sendo feito exatamente o contrário dentro da nossa sala de aula. Aqui é uma avaliação classificatória, onde eu tenho que olhar pra frente, eu não posso olhar para o lado, eu não posso ter uma aula antes para trocar experiências e informações com meus colegas. Se tivéssemos um "aulão" antes da prova teríamos um momento pra relaxar, tirar dúvida. É estressante também porque a sala fica muito cheia, muitos alunos de uma vez só fazendo provas, e sempre alguém te observando, não é constrangedor? Eu me sinto assim. (GF 01/ALINE)
}

Para Abrecht (1994, p. 18), a avaliação formativa deve ser vista como uma atitude, e não como um método. "Os grandes objetivos da avaliação formativa são, de facto, a conscientização, por parte do aluno, da dinâmica do processo de aprendizagem (objectivos, 
dificuldades e critérios)". Dito de outra forma, a avaliação formativa deve ajudar o aluno em relação à aprendizagem dos conteúdos.

Nesta mesma linha de pensamento, Perrenoud (1999) adverte que o professor, ao optar pela avaliação formativa, necessariamente deve considerar a organização das aulas, as estratégias, as práticas de ensino, o programa, os objetivos e as políticas estabelecidas na instituição. Nesse sentido, as falas dos alunos revelam contradições entre o que está previsto no Projeto Pedagógico do curso, no discurso dos professores, nas teorias estudadas e o que está presente nas estratégias e práticas vivenciadas. Um aulão, como reivindicado pela aluna Aline (GF01), poderia ser uma estratégia oportuna de aprendizagem.

\footnotetext{
A avaliação presencial [...] não é formativa [...] que eu veja o que eu errei, porque errei, e o que eu errei. Passam para o próximo módulo sem retorno. Consegui a média? Consegui! Mas vão ficar dúvidas naquelas questões que eu errei. A única coisa que vem é o gabarito [...] com o número de acertos. Nas atividades a distância, você preenche tudo, é diferente, o preceptor dá uns toques pra gente olha! Vocês precisam estudar mais, isso não está legal, e vocês agora são graduandos, nível superior, então melhoram esse linguajar-então, com isso, você acaba adquirindo um novo saber, você acaba realmente melhorando a partir dessa avaliação. E, na presencial, eu tive um pouco de dificuldade... (GF 02/CLAUDETE)
}

Concordamos com Villas Boas (2001), quando afirma que o professor é o principal mediador da aprendizagem do aluno quando avalia a partir das propostas de avaliação formativa. E, quando este apresenta objetivos claros em relação a esse processo, torna-se ainda mais fácil proporcionar feedback adequado aos seus alunos. Parece-nos que a queixa dos alunos em relação à ausência de retornos das correções das avaliações faz sentido e se justifica nas palavras de Villas Boas (2001), pois, segundo essa autora, o feedback deve ser utilizado para organizar o trabalho pedagógico e a aprendizagem dos alunos, pois é ele que fornece informações necessárias para o prosseguimento do processo educativo.

Eu não tenho acesso à prova que eu fiz, só ao gabarito [...] deveríamos ter uma revisão, pra gente ver onde é que aconteceu o erro. Não gosto de ver que eu errei e não ter como solucionar (GF 02/MARCIELE). 
Só que eu não quero só isso, eu quero que após a avaliação presencial essa prova retorne pra nós, para fazer uma revisão. Por que? O que eu errei eu não vou errar mais lá fora (GF 02/CLAUDETE).

Aqui, nota-se que o erro é compreendido por esses alunos como um momento de reflexão do processo de aprendizagem, e, mais uma vez, foi tema de discussão durante o grupo focal. Os erros cometidos pelos alunos nas avaliações, segundo Torre (2007, p. 19), devem ser um importante ponto de referência para sinalizar novos caminhos. Nas suas palavras, o erro deve ser entendido pelos professores "como um sintoma, e não como um mal, pois, do mesmo modo que a febre alerta de possíveis infecções, os erros na aprendizagem informam de estratégias inadequadas, de lacunas de conhecimento, de falhas na compreensão, de lapsos na execução".

b) Os ritos e os rituais da avaliação presencial num curso a distância: a reivindicação por um processo mais humanizado

Este tema, também, amplamente discutido nos grupos focais, foi, sem dúvida, o mais polêmico durante as discussões.

Peixoto (2004, p. 10) compreende ritos e rituais como partes de uma cultura - são costumes impregnados de simbologias e significados, "podem estar presentes nos mais variados espaços sociais e podem ser expressos de diferentes formas. E o espaço escolar, onde se dão inúmeras práticas educativas, não foge à regra".

Goldemberg (1985), apud Peixoto (2004, p. 11), faz referência a vários tipos de ritos e rituais, dentre os quais cita o da avaliação do rendimento escolar "como um ritual de seletividade, que identifica os estudantes competentes para excluir os demais".

É sobre o ritual da avaliação, expresso nas representações sociais dos alunos concluintes do curso de Pedagogia a distância, que vamos tecer algumas discussões.

Presente na maioria das falas dos participantes, para eles a avaliação, em razão da forma como é aplicada, tem sido tradicional, estressante, constrangedora e, muitas vezes, tem prejudicado o processo da avaliação.

A meu ver a avaliação é um pouco tradicional, não pelo que está escrito na prova, [...] o que só fortalece o nosso aprendizado, pois ela está contida nos roteiros, o que é cobrado da gente, mas a maneira como se aplica a prova é muito tradicional, 
eles colocam a gente em filas, como se fossemos alunos de quarta série, e falam pra gente não olhar pro lado senão vão tomar a prova. (GF 01/ALINE).

Eles recolhem todo o material É totalmente tradicional, senta um atrás do outro, todos ali na frente, uns 3 ou quatro fiscais na sala, a gente não pode virar pro lado. [...] Uma vez eu estava fazendo a avaliação e a minha borracha caiu no chão. Gente foi constrangedor - eu fui pegar e veio quase todo mundo em cima de mim, como se eu tivesse fazendo coisas erradas (GF 01/SAMARA).

Como percebemos, o ritual da avaliação tem sido um elemento negativo na constituição das representações sociais dos alunos sobre a avaliação. Para Peixoto (2004, p. 11-12), esses rituais estão impregnados na nossa cultura, eles refletem "a visão de mundo e as concepções de ensino, de escola, de aluno, que também se consolidaram ao longo da história do ensino e ainda hoje se mantêm, com poucas alterações, na quase totalidade das escolas".

Com relação às contribuições da teoria das representações sociais, vale indagarmos: que sentido esses rituais têm para a educação? É o mesmo de alguns tempos atrás? O que eles significam para os professores? E para os alunos? Em algum momento eles podem ser considerados bons, como aponta uma componente do grupo focal?

Concordo com alguns pontos que minhas colegas colocaram sobre a avaliação. Mas, eu também acho importante que a avaliação classificatória aconteça, mesmo que fique todo mundo muito tenso e nervoso, pois quando vem o resultado me sinto testada, sinto bem quando eu vejo a nota. Se errei, e tiro nota baixa, procuro estudar mais. Então, acho que pra mim é um incentivo. Sinceramente gosto do sistema de avaliação. Tem a formativa e a classificatória, acho importante todas elas (GF 02/EDNA).

Com exceção dessa aluna, parece que o ritual de avaliação no ensino a distância tem-se constituído como um momento de tensão e constrangimento, contrariando os princípios de uma avaliação formativa, defendida teoricamente pelos conteúdos estudados no curso.

Uma das características do grupo focal é a de possibilitar aos participantes dialogarem entre si, numa situação de inter-relação. Esses diálogos auxiliam a eficácia das 
entrevistas, impedindo, muitas vezes, opiniões tendenciosas ou falsas. A fala da participante seguinte evidencia isto:

\begin{abstract}
Apesar de não concordar com esse jeito de aplicar a prova, é bom lembrar que, no começo, não era assim, estas mudanças começaram quando eles misturaram todos os cursos para fazerem prova (Pedagogia, Matemática, Administração). Aí, começaram a colar, muita cola por sinal, muita mesmo, por isso adotaram esse tradicionalismo todo, não era dessa forma, a gente só tinha que virar pra frente, não havia três, quatro vigias na sala. A primeira prova que a gente fez, tinha uma pessoa só na sala. Aí tem que olhar pelos dois lados. Não foi a gente que colou, mas aconteceu, então por causa de outros todo mundo acaba perdendo (GF 01/MAILA).
\end{abstract}

A maioria concordou com a colega, mas disseram que era necessário retornar à aplicação da prova só para o curso de Pedagogia, e recomendaram, também, que o aplicador fosse um preceptor do próprio curso. Embora a discussão da cola não tenha tido continuidade durante a entrevista, foi possível observar que há um consenso entre os alunos acerca dessa questão - reconhecem que a cola realmente existia entre os alunos e pode ter sido esse o motivo que desencadeou tanto desconforto durante as provas.

É importante que a avaliação seja aplicada por quem esteve com a gente durante o processo de aprendizagem, mas não é, são outras pessoas e isso a torna mais estressante ainda (GF 01/VALDIRENE).

Acho essa questão histórica, na verdade, desde a primeira série, você é obrigada a ter nota, [...] isso causa medo, [...]você não pode olhar para o lado, para o outro, você não pode olhar pra frente, tem que ficar ali, aí deixa o lápis, bota a bolsa na frente, desliga o celular. Então isso vai criando uma tensão e você vai lembrando - é prova de novo, é avaliação. Não são as preceptoras que aplicam as provas e isso nos deixa mais tensos ainda. A gente nem sabe quem vai aplicar a prova, não é nosso preceptor, é quem não temos contato algum, a pessoa entra dentro da sala e friamente diz: é fila, a bolsa pra frente, desliga o celular, tem um horário. E aí fica tudo tenso, e você fica ali, ai meu Deus vou passar de hora, ai eu não vou conseguir, [...]não vai dar tempo de eu preencher o gabarito e fazer as redações. Entendeu! Então vai criando esse medo, essa tensão né. O horário também não é bom, deveria se de manhã, - você vem com a cabeça fresca. Ficamos tensas porque precisamos de uma média [...] (GF 02/CLAUDETE). 
Embora as mazelas de nosso sistema de ensino sejam históricas e determinadas por uma gama de fatores complexos, como expõe a participante do grupo focal, compreendemos que a avaliação não pode se resumir apenas num momento de provas. Deve ser realizada num processo contínuo e concomitante à aprendizagem do aluno.

A superação de tais problemas "supõe discussões, estudos, troca de experiências, elementos necessários a uma mudança de mentalidade e uma consequente mudança de paradigmas", sugere Peixoto (2004, p. 15).

Concordo com o nervosismo, ficamos tensas. Já estamos no nível superior, somos quase pedagogos, não precisa de fila, pedir para colocar a bolsa em outro lugar e dizer que não pode olhar pro lado - por favor eu desejo não ter que chamar a atenção (GF 02/EDNA).

Concordo que é necessário sim a avaliação presencial, é exigência do MEC, não concordo é com o método tradicionalista -fica sentadinha uma atrás da outra, não pode olhar pro lado, ameaças de tomar a prova. Esse tipo de coisa, é constrangedor pra gente, me incomoda a forma como eles nos avaliam, penso que isso deve ser revisto (GF 02/MARCIELE).

Segundo Zabala (1998), a avaliação formativa ocorre somente onde há um clima de respeito mútuo, de colaboração, de cumplicidade e de compromisso com o processo de aprendizagem. O que se percebe nas falas das entrevistadas é que esse clima de colaboração, de cumplicidade, fica dificultado nessa modalidade de ensino, em virtude da fragmentação do trabalho docente: quem responde pela avaliação não é quem foi responsável pelo processo de ensino e aprendizagem, aliás essa função também fica diluída entre quem pensa a disciplina e quem executa.

c) Avaliação a distância na percepção dos alunos: importante, necessária e conduz a aprendizagem

Nesta unidade foram agrupados os diálogos que demonstram a forma como os alunos percebem a avaliação. A pergunta motivadora foi a seguinte: se um conhecido seu, estudante de outra instituição, que não conhece o sistema de avaliação na modalidade a distância lhe perguntasse o que você acha das avaliações, o que responderia para ele? Como é a avaliação da aprendizagem na educação a distância no seu curso? Qual a sua percepção 
de avaliação? - percepção, entendida aqui, como a maneira como nós vemos, julgamos, conceituamos, qualificamos a avaliação.

A única diferença que eu vejo da avaliação em cursos a distância do ensino presencial é que eles fazem mais avaliações do que a gente (GF 01/ALINE).

Nossa avaliação é difícil porque só fazemos uma só durante um período de 6 meses (GF 01/SAMARA).

Mas, em compensação, nós temos as atividades também, que a gente não pode esquecer (GF 01/PEDRO).

Sim, facilita, até porque o que ajuda muito são essas atividades, que a gente faz em sala de aula, até mesmo nas provas (GF 01/SAMARA).

Durante as entrevistas, o termo avaliação esteve constantemente associado à prova escrita, ritual, desconforto, exame, reprovação. Já as outras atividades realizadas por eles foram lembradas, poucas vezes, como sendo integrantes do processo de avaliação. Notamos, aqui, que, de modo geral, os alunos estão construindo representações sobre avaliação ancoradas em processos que denotam uma concepção pedagógica arcaica, tradicional. Em se tratando de curso de formação de professores, essa representação pode ser preocupante, uma vez que esses sujeitos estão sendo preparados para atuarem no campo da educação.

Por outro lado, há quem reconheça isso e discuta no grupo:

Avaliação é primordial, é necessária, e que é um crescimento, mas pena que ela é tradicional, e classificatória. Aqui você tem que estudar, se você não estudar, não passa. Não é porque é a distância que você pode enrolar mais (GF 02/LUCIMAR).

O curso é muito bom, quem quer estudar mesmo, com comprometimento, quem quer aprender consegue, de uma forma dinâmica, de uma forma que você já sai daqui pronto pra encarar uma sala de aula com certeza, e um concurso público também. E tem várias colegas nossas que já conseguiram, agora o nosso meio de avaliar ainda é aquele antigo (GF 02/MARLUCE). 
Realmente acho que a avaliação no curso a distância, comparado com outra graduação presencial que fiz é muito boa, ótima, porque ela está cobrando, e o que ela cobra, a gente vai lá na frente e dá em troca (GF 02/MARIA APARECIDA).

Ser avaliado é bom pra gente, pois revemos o que estudamos, só a maneira de aplicar a prova é que é constrangedor. A avaliação nos leva a refletir sobre todo o nosso processo de aprendizagem, então ela revê os roteiros, ela revê as atividades, os estudos independentes, tudo ela revê. A gente tem que estar ali ligados, situados em todas as leituras obrigatórias, porque tudo isso é revisto na hora da prova. É estimulante, é gratificante, a gente vê que não estudou em vão, mesmo com todo método que a prova é aplicada, aquilo que está sendo cobrado na prova, é exatamente o que aprendemos e estudamos, mesmo que a nota não seja tão boa (GF 01/ELIANE).

Realizar avaliações, de modo que elas cumpram a sua função, rever o que foi estudado e refletir sobre o processo de aprendizagem é o que aponta Belloni (1999, p. 52): "devemos trabalhar na direção da construção de uma cultura de avaliação, isto é, a avaliação incorporada de forma institucionalizada e como um espaço de reflexão sistemática, com vistas à elaboração de subsídios para a tomada de decisão".

Alguns já atribuem à avaliação benefícios para a vida profissional:

A minha aprovação num concurso público eu devo a esse curso e às avaliações que realizei, foram elas que me ajudaram, quando me perguntaram sobre os autores, suas teorias, eu soube responder. [...]A prova da prefeitura de Cariacica também foi sobre as teorias que estudamos aqui, e eu passei, e eu entendi que vale a pena estudar (GF 02/EDNA).

Quando as pessoas me perguntam se eu faço faculdade a distância e digo que faço faculdade a distância, mas não distante. Porque tem muita gente que faz uma faculdade presencial e está distante, não está na sala de aula. E para mim esse curso só veio a complementar minha visão de mundo, aumentou muito sabe! (GF 02/MARCIELE).

Eu acredito que a avaliação é necessária, ela se faz necessária, e ela só vem contribuir com o nosso crescimento. Não é brincadeira não, não é só ir lá e responder se é verdadeiro ou falso. E principalmente a redação -, é boa [a avaliação] (GF 02/EDNA). 
Mesmo questionando o ritual da avaliação, e o fato de ela ser classificatória e excludente, os alunos reconhecem a sua importância como elemento constituinte do processo de aprendizagem.

\section{$5 \quad$ Considerações Finais}

As contradições entre teoria e prática, vivenciadas pelos sujeitos durante o curso, ganham uma dimensão significativa neste estudo. Parece que a forma como os alunos são avaliados, em meio a contradições, em que se apregoa uma teoria e se oferecem outras práticas, tem contribuído para construções de representações sociais pautadas no descontentamento e no desconforto em relação à avaliação. Mais preocupante ainda se tornam essas representações pelo fato de os sujeitos investigados fazerem parte de um curso de formação de professores. Tomam-se, aqui, as contribuições da Teoria das Representações Sociais, considerando o que Madeira (2001, p. 127) aponta: "as RS são fenômenos complexos que dizem respeito ao processo pelo qual o sentido de um objeto é estruturado pelo sujeito, no contexto de suas relações". Gentile, Lima e Mazzotti (2011, p. 337) acrescem que, "na relação com o outro, o sujeito constrói o seu sentido com o objeto, da mesma forma que é construído por ele". Isso significa que a utilização da Teoria das Representações Sociais na educação permite estudar os objetos no dinamismo em que são constituídos.

Hoffmann (2005, p.12) ilustra que seus estudos vêm demonstrando, claramente, que as contradições entre o discurso e a prática, no ato de avaliar, encontram explicações na concepção de avaliação dos professores, "reflexo de sua história de vida como aluno e professor", e recomenda: "temos de desvendar contradições e equívocos teóricos dessa prática, construindo um 'resignificado' para a avaliação e desmistificando-a de fantasmas de um passado ainda muito em voga".

Com relação aos processos de objetivação e ancoragem - constituintes das representações aqui identificadas -, parece que nos levam a inferir que os sujeitos deste estudo, a partir de suas vivências, falas, imagens, opiniões, estão organizando e materializando suas representações em sentimentos que denotam ser a avaliação primordial e necessária para a aprendizagem no curso. Porém, ao mesmo tempo, eles têm convivido 
com contradições entre o que se ensina na teoria e o que se vivencia na prática, o que os leva a reivindicar um processo de avaliação mais humanizado.

\section{Referências}

ABRECHT, R.A Avaliação Formativa. Porto: Edições ASA, 1994.

BARDIN, L. Análise de Conteúdo. Lisboa: Edições 70, 1977.

BARRETO, R. G. (Org.). Tecnologias educacionais e educação a distância: avaliando políticas e práticas. Rio de Janeiro: Quartet, 2003.

BELLONI, I. Avaliação Institucional: um instrumento de democratização da educação. Linhas Críticas, Brasília, vol. 5, no 9, p. 7-30, jul-dez de 1999.

BRASIL - MEC. Ministério da Educação. Decreto Federal no 5.622, de 19 de dezembro de 2005. Brasília: Diário Oficial da União, 20 dez. 2005.

BRASIL. Conselho Nacional de Educação. Resolução n.1, 15.5.2006. Brasília: Diário Oficial da União, n.92, seção 1, p.11- 12, 16 maio 2006.

BRASIL - MEC. Ministério da Educação. Secretaria de Educação a distancia. Referenciais de qualidade para Educação Superior à Distância. Brasília, 2007.Disponível em: <http://www.planalto.gov.br/ccivil_03/_Ato2004-2006/2005/Decreto/D5622.htm>. Acesso em: 23 abr. 2012.

CABECINHAS, R. Representações sociais, relações intergrupais e cognição social. Universidade do Minho - Portugal. Paidéia, v. 14, n.28, p.125-137, 2004.

CHAMON, E. M. Q. O. Representação social da pesquisa pelos doutorandos em ciências exatas. Estudos e Pesquisas em Psicologia, Rio de Janeiro, Ano 6, n. 2, 20 semestre, p. 21-33, 2006.

ESTEBAN, M. T. (Org.) Escola, currículo e avaliação. 3 ed. São Paulo: Cortez, 2008. 
FLICK, U. Métodos de Pesquisa: Introdução a Pesquisa Qualitativa. Tradução de Joice Elias Costa. 3 ed. Porto Alegre: Artmed, 2009.

GENTILE, M; LIMA, RCP; MAZZOTTI, T. Saberes da prática na formação: representações sociais de alunos de Pedagogia. Diálogo Educacional. Curitiba, v 11, n.33, p. 331-351, 2011. GUARESCHI, P. A. Representações Sociais: avanços teóricos e epistemológicos. Temas em Psicologia da SBP. Porto Alegre. Vol. 8, n. 3, 2000, p. 249-256.

GUARESCHI, T.; NAUJORKS, M. I. As representações sociais de professores acerca da aprendizagem de alunos com distúrbios globais do desenvolvimento. In: REUNIÃO ANUAL ANPED, 29, 2006, Caxambu. Anais... Rio de janeiro: ANPED, 2006. Disponível em: http://www.anped.org.br/reunioes/29ra/trabalhos/trabalho/GT15-2192--Int.pdf. Acesso em: 13 fev. 2012.

HAYDT, R. C. Avaliação do processo ensino-aprendizagem. São Paulo: Ática, 2000.

HOFFMANN, J.M.L. Avaliação mediadora: uma prática em construção da pré-escola à universidade. Porto Alegre: Educação e Realidade, 1995.

JODELET, D. Représentations socials un domaine en expansion. In: JODELET, D. (Ed.) Les representations sociales. Paris: PUF, 1989, p. 31-61.

JODELET, D. Représentation social: phénomènes, concept et théorie. In: MOSCOVICI, S. (Ed.). La psychologie sociale. Paris: Presses Universitaires de France, 1992. p. 357-389.

LUCKESI, S.C. Avaliação da aprendizagem: componente do ato pedagógico. São Paulo: Cortez, 2011.

MADEIRA, M. Representações sociais e educação: importância teórico-metodológica de uma relação. In: MOREIRA, A. S. P. (Org.). Representações sociais: teoria e prática. João Pessoa: Universitária, 2001. p. 123-146.

MINAYO, M.C. de S. (Org.). Pesquisa social: teoria, método e criatividade. 22. ed. Rio de Janeiro: Vozes, 2003.

MOSCOVICl, S. La Psychanalyse, son image et son public. Paris: Press Universitary de France, 1961 
MOSCOVICI, S. A representação social da psicanálise. Rio de Janeiro: Zahar, 1978.

MOSCOVICl, S. (Org.). Pensamiento y vida social. Barcelona/Buenos Aires/México: Paidós, 1984.

MOSCOVICl, S. Representações sociais: investigações em psicologia social. Petrópolis: Vozes, 2003.

PEIXOTO, M. S. S. (Org.) Programa de apoio ao desenvolvimento da Educação Municipal PRADEM. Avaliando para crescer: Parâmetros de Avaliação de São Sebastião do Passé - BA. Salvador; UFBA, FCM, Fundação FORD, Série Documentos Avaliação Educacional, 2004.

PERRENOUD, P. Avaliação: da excelência à regulação das aprendizagens - entre duas lógicas. Porto Alegre: Artes Médicas Sul, 1999.

RESENDE, M. R.; VIEIRA, V. M.O. A formação do professor de matemática na modalidade a distância: a aprendizagem em discussão. In: REUNIÃO ANUAL DA ANPED, 33, 2010, Caxambu. Anais... Rio de Janeiro: ANPED, 2010. Disponível em: <http://www.anped.org.br/33encontro/app/webroot/files/file/Trabalhos\%20em\%20PDF/GT 19-6704--Int.pdf>. Acesso em: 17 jul.2013.

SOUSA, C. P. Significado da avaliação do rendimento escolar: uma pesquisa com especialistas da área. In: SOUSA, C.P. (Org). Avaliação do rendimento escolar. 11 ed. Campina: Papirus. 2003. p.109-138.

TORRE, S. Aprender com os erros: o erro como estratégia de mudança. Porto Alegre:

Artmed, 2007.

TRINDADE, Z. A; SANTOS,M. F. S; ALMEIDA, A. M. O. Ancoragem: notas sobre consensos e dissensos. In:

Technopolitik, 2011. p. 101-121. (Orgs). Teorias das Representações Sociais: 50 anos. Brasília:

UnIVERSIDADE DE UBerABA. Projeto Politico Pedagógico do Curso de Pedagogia na Modalidade a Distância. 2007.

VASCONCELLOS, C. S. Avaliação da aprendizagem: práticas de mudanças. São Paulo: Libertad - Centro de Formações e Assessoria Pedagogia, 1998. 
VILLAS BOAS, B. M. F. Avaliação formativa e formação de professores: ainda um desafio. Linhas Críticas, Brasília, v. 12, n. 22, p.159-180, jun. 2001.

ZABALA, A. A prática educativa: como ensinar. Porto Alegre: Artmed, 1998.

Enviado em Abril/2012

Aprovado em Maio/2013 